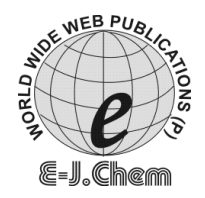

http://www.e-journals.net
ISSN: 0973-4945; CODEN ECJHAO

E-Journal of Chemistry 2009, 6(3), 639-650

\title{
Ion Exchange Properties of a Terpolymer Resin Derived from 2, 4-Dihydroxybenzaldehyde, Oxamide and Formaldehyde
}

\author{
M. V. TARASE, W. B. GURNULE* ${ }^{*}$ and A. B. ZADE \\ Department of Chemistry, Laxminarayan Institute of Technology, \\ Rashtrasant Tukdoji Maharaj, Nagpur University, Nagpur-440 010, India. \\ *Department of Chemistry, Kamla Nehru College, \\ Sakkaradara, Nagpur-440 009. India. \\ wbgurnule@yahoo.co.in
}

Received 29 August 2008; Accepted 10 October 2008

\begin{abstract}
Terpolymer resins (2,4-DHBOF) were synthesized by the condensation of 2,4-dihydroxybenzaldehyde and oxamide with formaldehyde in the presence of hydrochloric acid as catalyst, proved to be selective chelation ion exchange terpolymer resins for certain metals. Chelation ion exchange properties of these polymers were studied for $\mathrm{Fe}^{+3}, \mathrm{Cu}^{+2}, \mathrm{Hg}^{+2}, \mathrm{Cd}^{+2}, \mathrm{Co}^{+2}, \mathrm{Zn}^{+2}$, $\mathrm{Ni}^{+2}$ and $\mathrm{Pb}^{+2}$ ions. A batch equilibrium method was employed in the study of the selectivity of the distribution of a given metal ions between the polymer sample and a solution containing the metal ion. The study was carried out over a wide $\mathrm{pH}$ range and in a media of various ionic strengths. The polymer showed a higher selectivity for $\mathrm{Fe}^{+3}, \mathrm{Cd}^{+2}$ and $\mathrm{Co}^{+2}$ ions than for $\mathrm{Cu}^{+2}, \mathrm{Hg}^{+2}, \mathrm{Zn}^{+2}, \mathrm{Ni}^{+2}$ and $\mathrm{Pb}^{+2}$ ions.
\end{abstract}

Keywords: Synthesis, Ion-exchangers, Batch equilibrium, Distribution ratio, Resin

\section{Introduction}

Ion exchange may be defined as the reversible exchange of ions between the substrate and surrounding medium. Ion exchange technique can remove traces of ion impurities from water/process liquors and given out a product of ultra pure quality in a single efficient and techno-economically viable manner. Ion exchangers are widely used in analytical chemistry, hydrometallurgy, antibiotics, purification and separation of radioisotopes and find large application in water treatment and pollution control ${ }^{1,2}$. Lutfor $e t a l^{3}$ prepared a chelating ion exchange resin containing amidoxime functional group. The chelating poly (amidoxime) resin was characterized by FTIR spectra, TG and DSC analyses. The chelating behavior of 
the prepared resin was studied with $\mathrm{Cu}(\mathrm{II}), \mathrm{Zn}$ (II), $\mathrm{Ni}$ (II), $\mathrm{Cd}(\mathrm{II})$ and $\mathrm{Pb}$ (II) metal ions. Samir et $a l^{4}$ synthesized ion exchange resin from 8-quinolinyl methacrylate and characterized by conventional methods. The thermal analysis was carried out using TGA and DSC. The metal ion uptake capacities of synthesized copolymers were estimated by batch equilibration method using different metal ion solutions under different experimental conditions.

Three phenol-formaldehyde chelating resins, poly (8-hydroxyquinoline-5,7 diylmethylene), poly (8-hydroxyquinoldine-5,7 diylmethylene) and poly (2-aminophenol-5,7 diylmethylene) were synthesized and characterized by Ebraheem ${ }^{5}$. The chelating characteristics of these polymers were studied by a batch equilibrium technique. The ion exchange capacity, effect of electrolyte on metal ion up take, rate of metal uptake and distribution of metal ion at different $\mathrm{pH}$ with resin copolymer derived from thiosemicarbazone derivatives of phenolic compound shows higher order than the resin copolymer derived from semicarbazone derivatives ${ }^{6}$. Recently much work has been carried out to study the ion exchange properties of anchoring functional chelating groups on the polymeric network. But as compared to anchored resins, the synthesized resins are more advantageous because the synthesized insoluble functionalized polymer can provide good stability and good flexibility in working conditions.

Rivas B. L ${ }^{7}$ synthesized crosslinked poly [3-(methacryloyl- amino)-propyl]-dimethyl(3sulfopropyl)ammoniumhydroxide-co-2-acryl-amidoglycolic acid [PCMAAPDSA-coAGCO] by radical polymeri-zation and tested the synthesized polymer as an absorbent under competitive and non-competitive conditions for $\mathrm{Cu}$ (II), $\mathrm{Cd}$ (II), $\mathrm{Hg}$ (II), $\mathrm{Zn}$ (II), $\mathrm{Pb}$ (II) and $\mathrm{Cr}$ (III) by batch and column equilibrium procedures. They reported that resin metal ion equilibrium was achieved before $1 \mathrm{~h}$. the resin showed a maximum retention capacity value of 1.084 m.equ. $\mathrm{g}^{-1}$ for $\mathrm{Hg}(\mathrm{II})$ at $\mathrm{pH}$ 2. The recovery of the resin was investigated at $20{ }^{0} \mathrm{C}$ under different concentration of $\mathrm{HNO}_{3}$ and $\mathrm{HClO}_{4}$.

Jadhao M.M. and coworker ${ }^{8}$ synthesized a terpolymer resin by condensation of 2,2'dihydroxybiphenyl and formaldehyde in the presence of acid catalyst. They studied chelating ion exchange properties of this polymer for $\mathrm{Fe}(\mathrm{III}), \mathrm{Cu}(\mathrm{II}), \mathrm{Ni}(\mathrm{II}), \mathrm{Zn}$ (II), $\mathrm{Cd}(\mathrm{II})$ and $\mathrm{Pb}(\mathrm{II})$ ions. A batch equilibrium method was employed in the study of the selectivity of metal ion uptake involving the measurement of the distribution of a given metal ion between the polymer sample and a solution containing metal ions. The study was carried out over a $\mathrm{pH}$ range and in media of various ionic strengths. They reported that the polymer showed a higher selectivity for $\mathrm{Fe}(\mathrm{III}), \mathrm{Cu}(\mathrm{II})$ and $\mathrm{Ni}(\mathrm{II})$ than for $\mathrm{Co}(\mathrm{II}), \mathrm{Zn}(\mathrm{II})$ $\mathrm{Cd}(\mathrm{II})$ and $\mathrm{Pb}(\mathrm{II})$ ions.

So for no resin based on 2,4-dihydroxybenzaldehyde-oxamide-formaldehyde in acidic media has been synthesized for the quantitative separation of transition metal ions. As industrial influence often rich in transition metal ions, removal of these metals use an important task for industries. Therefore we have studied the use of ion exchanger for removal and separation of heavy metal ions. In this paper synthesis and characterization of the above resin are reported together with the condition for the effective separation of transition metal ions.

\section{Experimental}

The chemicals 2,4-dihydroxybenzaldehyde, oxamide and formaldehyde (37\%) used are of A. R. grade and chemically pure which is purchased from Merck. Solvents like $\mathrm{N}, \mathrm{N}$-dimethyl formamide and dimethylsulphoxide were used after distillation. 


\section{Preparation of 2, 4-DHBOF terpolymers}

The 2,4-DHBOF-I terpolymer resin was prepared by condensing 2, 4dihydroxybenzaldehyde $(1.66 \mathrm{~g}, 0.1 \mathrm{~mol})$ and oxamide $(0.88 \mathrm{~g}, 0.1 \mathrm{~mol})$ with formaldehyde $(7.5 \mathrm{M}, 0.2 \mathrm{~mol})$ in the presence of $2 \mathrm{M} \mathrm{HCl}$ as a catalyst at $126 \pm 2{ }^{\circ} \mathrm{C}$ in an oil bath for $5 \mathrm{~h}$ (Scheme 1). The brown colored solid product obtained was immediately removed and extracted with diethyl ether to remove excess of 2, 4-dihydroxybenzaldehyde-formaldehyde copolymer, which might be present along with the 2, 4-DHBOF-I terpolymer. It was further purified by dissolving in $8 \% \mathrm{NaOH}$ and then filtered. The terpolymer was then reprecipited by drop wise addition of $1: 1(\mathrm{v} / \mathrm{v})$ conc. $\mathrm{HCl} /$ water with constant stirring and filtered. The process was repeated twice. The resulting polymer sample was washed with boiling water and dried in a vacuum at room temperature. The purified terpolymer resin was finely ground to pass through 300-mesh size sieve and kept in a vacuum over silica gel. The yield of the terpolymer was found to be about $80-83 \%$ (Table 1 ).

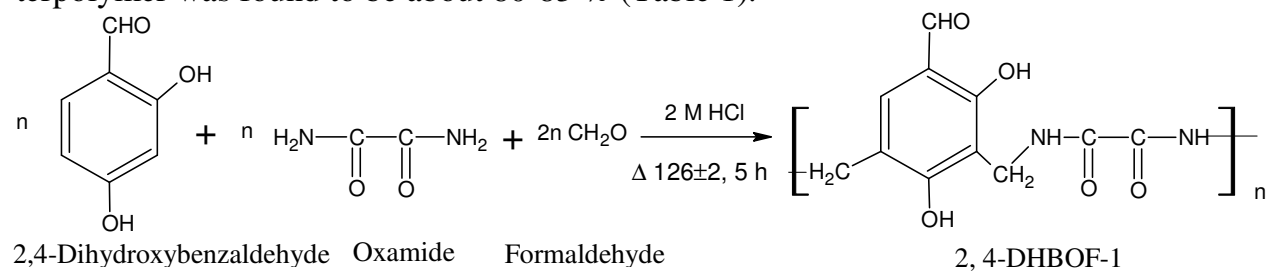

Scheme 1. Synthesis of 2, 4-DHBOF-I terpolymer.

Table 1. Synthesis and physical data of 2, 4-DHBOF terpolymers resins.

\begin{tabular}{|c|c|c|c|c|c|}
\hline \multirow[b]{2}{*}{ Terpolymers } & \multicolumn{3}{|c|}{ Reactants } & \multirow[b]{2}{*}{$\begin{array}{c}\text { Catalyst } \\
2 \mathrm{M} \mathrm{HCl}(\mathrm{aq}) \mathrm{mL}\end{array}$} & \multirow[b]{2}{*}{ Yield, \% } \\
\hline & $\begin{array}{c}\text { 2,4-DHB, } \\
\text { m mol. }\end{array}$ & $\begin{array}{c}\text { Oxamide, } \\
\text { mol. }\end{array}$ & $\begin{array}{c}\text { Formaldehyde, } \\
\text { mol. }\end{array}$ & & \\
\hline 2,4-DHBOF-I & 0.1 & 0.1 & 0.2 & 200 & 82.6 \\
\hline 2,4-DHBOF-II & 0.2 & 0.1 & 0.3 & 200 & 83.9 \\
\hline 2,4-DHBOF-III & 0.3 & 0.1 & 0.4 & 200 & 81.6 \\
\hline 2,4-DHBOF-IV & 0.4 & 0.1 & 0.5 & 200 & 80.3 \\
\hline
\end{tabular}

Similarly, the other terpolymers viz. 2, 4-DHBOF-II, 2, 4-DHBOF-III, 2, 4-DHBOF-IV were synthesized by varying the molar ratios of the reacting monomers i. e. 2, 4-dihydroxybenzaldehyde, oxamide and formaldehyde in the ratios of 2:1:3, 3:1:4, 4:1:5 respectively.

\section{Analytical and physicochemical studies}

The intrinsic viscosities were determined using a Tuan-Fuoss viscometer ${ }^{9}$ at six different concentrations ranging from $0.3 \mathrm{wt} \%$ to $0.05 \mathrm{wt} \%$ of resin in DMF at $300{ }^{\circ} \mathrm{C}$. Intrinsic viscosity ( $\eta$ ) was calculated by the Huggin's ${ }^{9}$ eq. (1) and Kraemer ${ }^{9}$ eq (2).

The elemental analysis was carried out on a Perkin Elmer 2400 Elemental Analyser instruments. The UV-Visible studies were out carried using Hitachi 330 UV-VIS-NIR Spectrometer in the range $200-850 \mathrm{~nm}$. The Infrared spectrum was recorded in the region of $500-4000 \mathrm{~cm}^{-1}$ on Perkin Elmer Spectrum RX1 FT-IR Spectrometer. ${ }^{1} \mathrm{H}-\mathrm{NMR}$ studied using Bruker Avance-II FT-NMR Spectrometer in DMSO- $\mathrm{d}_{6}$ solvent. All the analytical and spectral studies for the newly synthesized terpolymer were carried out at Sophisticated Analytical Instrumentation Facility (SAIF) Punjab University, Chandigarh.

\section{Ion exchange properties}

To decide the selectivity of 2, 4-DHBOF terpolymers, we studied the influence of various electrolytes, the rate of metal uptake and distribution of metal ions between the terpolymer 
and solution. The results of the batch equilibrium study carried out with the terpolymer samples are presented in Tables 5-7.

Determination of metal uptake in the presence of electrolytes of different concentrations

The terpolymer sample $(25 \mathrm{mg})$ was suspended in an electrolyte solution of $\mathrm{NaNO}_{3}(25 \mathrm{~mL})$ of known concentration. The $\mathrm{pH}$ of the suspension was adjusted to the required value by using either $0.1 \mathrm{~N} \mathrm{HCl}$ or $0.1 \mathrm{~N} \mathrm{NaOH}$. The suspension was stirred for a period of $24 \mathrm{~h}$ at $25^{\circ} \mathrm{C}$. To this suspension $2 \mathrm{~mL}$ of $0.1 \mathrm{M}$ solution of the metal ion was added and the $\mathrm{pH}$ was adjusted to the required value. The mixture was again stirred at $25^{\circ} \mathrm{C}$ for $24 \mathrm{~h}$ and filtered. The solid was washed and the filtrate and washings were combined and the metal ion content was determined by titration against standard EDTA. The amount of metal ion uptake of the polymer was calculated from the difference between a blank experiment without polymer and the reading in the actual experiments. The experiment was repeated in the presence of other two electrolytes such as $\mathrm{NaCl}$ and $\mathrm{NaClO}_{4}$.

\section{Evaluation of the rate of metal uptake}

In order to estimate the time required to reach the state of equilibrium under the given experimental conditions, a series of experiments of the type describe above were carried out, in which the metal ion taken up by the chelating resins was determined from time to time at $25{ }^{\circ} \mathrm{C}$ (in the presence of $25 \mathrm{~mL}$ of $1 \mathrm{M} \mathrm{NaNO}_{3}$ solution). It was assumed that under the given conditions, the state of equilibrium was established within $24 \mathrm{~h}$. The rate of metal ions uptake is expressed as percentage of the amount of metal ions taken up after a certain time related to the time, which required for the state of equilibrium.

\section{Evaluation of the distribution of the metal Ions at different $\mathrm{pH}$}

The distribution of each one of the five metal ions i.e. $\mathrm{Fe}^{+3}, \mathrm{Cu}^{+2}, \mathrm{Hg}^{+2}, \mathrm{Cd}^{+2}, \mathrm{Co}^{+2}, \mathrm{Zn}^{+2}$, $\mathrm{Ni}^{+2}$ and $\mathrm{Pb}^{+2}$ between the polymer phase and the aqueous phase was determined at $2{ }^{\circ} \mathrm{C}$ and in the presence of a $1 \mathrm{M} \mathrm{NaNO}_{3}$ solution. The experiments were carried out as described above at different $\mathrm{pH}$ values. The distribution ratio ' $\mathrm{D}$ ' is defined by eq. (3).

$$
\mathrm{D}=\frac{\mathrm{Wt} .(\mathrm{mg}) \text { of metal ions taken up by } 1 \mathrm{~g} \text { of terpolymer }}{\text { Wt. }(\mathrm{mg}) \text { of metal ion present in } 1 \mathrm{~mL} \text { of terpolymer }}
$$

\section{Results and Discussion}

The terpolymers which have been use in the present investigation were prepared by the reaction scheme 1 . The resin sample was brown in color, insoluble in commonly used solvent, but was soluble in DMF, DMSO, THF, pyridine, concentrated $\mathrm{H}_{2} \mathrm{SO}_{4}$. No precipitation and degradation occurs of resin in all the solvents. These resins were analyzed for carbon, hydrogen and nitrogen content (Table 2).

\section{Viscometric study}

Viscometric measurements were carried out in DMF solution at $30{ }^{\circ} \mathrm{C}$ using a Tuan Fouss ${ }^{9}$ viscometer. Reduced viscosity versus concentration $(3 \%-0.5 \%)$ was plotted for each set of data. The intrinsic viscosity [ $\eta$ ] was determined by the corresponding linear plots (Figure 1). The following equations were used to determine Huggin's ${ }^{9}$ and Krammer's ${ }^{9}$ constant, respectively:

$$
\begin{aligned}
& \eta_{\text {sp. }} / C=[\eta]+k_{1} \cdot[\eta]^{2} . C \\
& \ln \eta_{\text {rel. }} / C=[\eta]-k_{2 .}[\eta]^{2} . C
\end{aligned}
$$




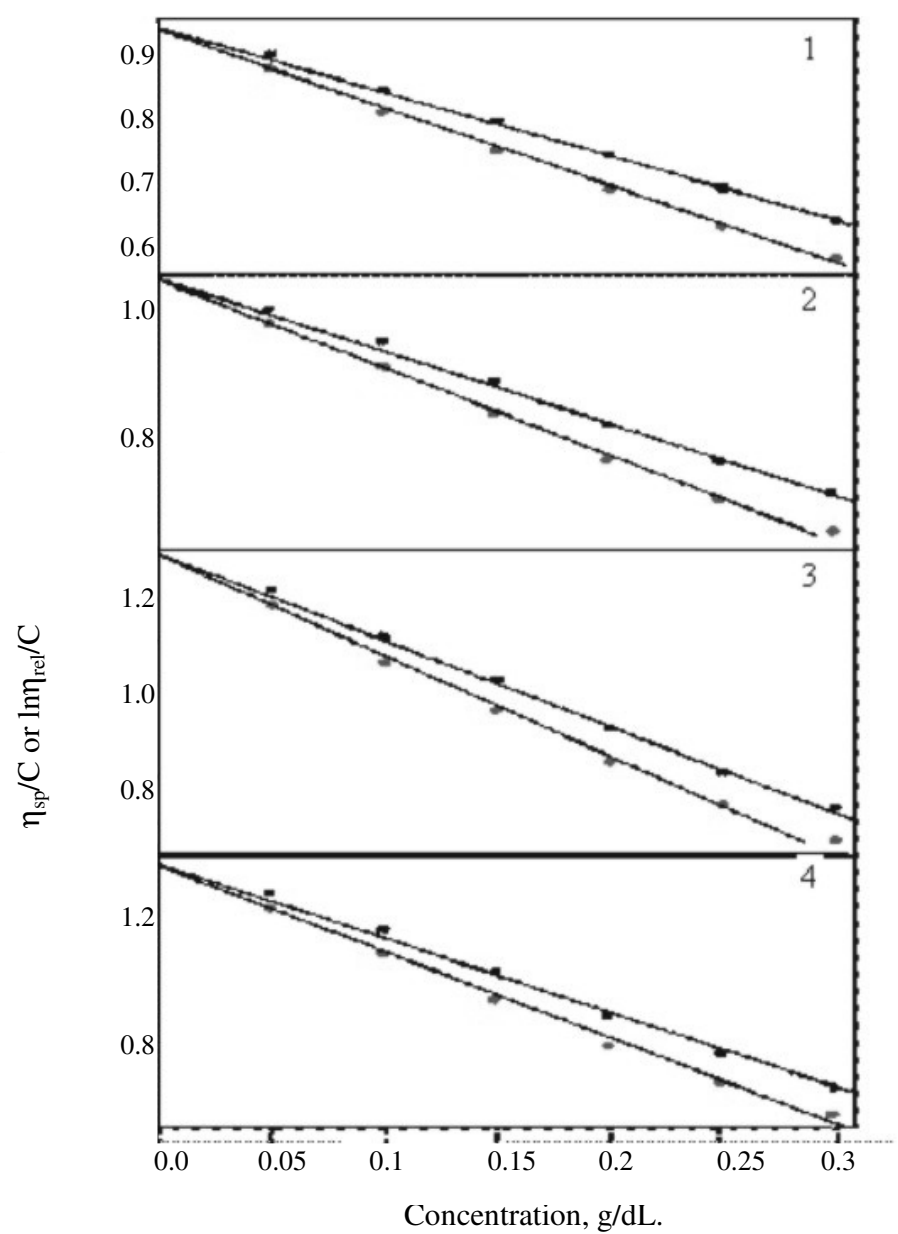

Figure. 1. Viscometric plots of terpolymers (1) 2, 4-DHBOF-I, (2) 2, 4-DHBOF-II, (3) 2, 4 DHBOF-III, (4) 2, 4-DHBOF-IV

According to above relations, a plot of $\eta_{\text {sp }} / \mathrm{C}$ and $\eta_{\text {rel }} / \mathrm{C}$ against $\mathrm{C}$ were linear with slopes of $k_{1}$ and $k_{2}$ respectively. Intercepts on the viscosity function axis gave [ $\eta$ ] valid in both plots The calculated values of the constants $k_{1}$ and $k_{2}$ for the intrinsic viscosities (Table 2) satisfy the relation $k_{1}+k_{2}=0.5$ favourably ${ }^{10}$. It was observed that terpolymers having higher Mn show a higher value of $[\eta]$.

Table 2. Elemental analysis data of 2, 4-DHBOF terpolymers resins.

\begin{tabular}{|c|c|c|c|c|c|c|c|}
\hline \multirow{3}{*}{ Terpolymers } & \multicolumn{6}{|c|}{ Elemental analysis, \% } & \multirow{3}{*}{ 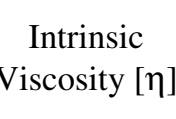 } \\
\hline & \multicolumn{2}{|c|}{$\mathrm{C}$} & \multicolumn{2}{|c|}{$\mathrm{H}$} & \multicolumn{2}{|c|}{$\mathrm{N}$} & \\
\hline & Calc. & Found & Calc. & Found & Calc. & Found & \\
\hline 2,4-DHBOF-I & 52.8 & 52.9 & 4.0 & 4.09 & 11.2 & 11.17 & 0.91 \\
\hline 2,4-DHBOF-II & 57.0 & 56.8 & 4.0 & 4.03 & 7.0 & 6.94 & 1.04 \\
\hline 2,4-DHBOF-III & 58.9 & 58.7 & 4.0 & 4.09 & 5.09 & 5.01 & 1.23 \\
\hline 2,4-DHBOF-IV & 60.0 & 59.9 & 4.0 & 4.06 & 4.0 & 3.94 & 1.36 \\
\hline
\end{tabular}




\section{Electronic spectra}

The UV-visible spectra (Figure 2) of all 2, 4-DHBOF terpolymer samples in pure DMSO were recorded in the region $190 \mathrm{~nm}-800 \mathrm{~nm}$. All the four 2,4-DHBOF terpolymers samples displayed two characteristic broad bands at $280 \mathrm{~nm}$ and $320 \mathrm{~nm}$. These observed position for absorption bands indicate the presence of a carbonyl $(>\mathrm{C}=\mathrm{O})$ group having a carbon oxygen double bond which is in conjugation with the aromatic nucleus. The later band can be accounted for a $\pi \rightarrow \pi^{*}$ transition while the former band (less intense) may be due to a $n \rightarrow \pi^{*}$ transitions ${ }^{11}$.

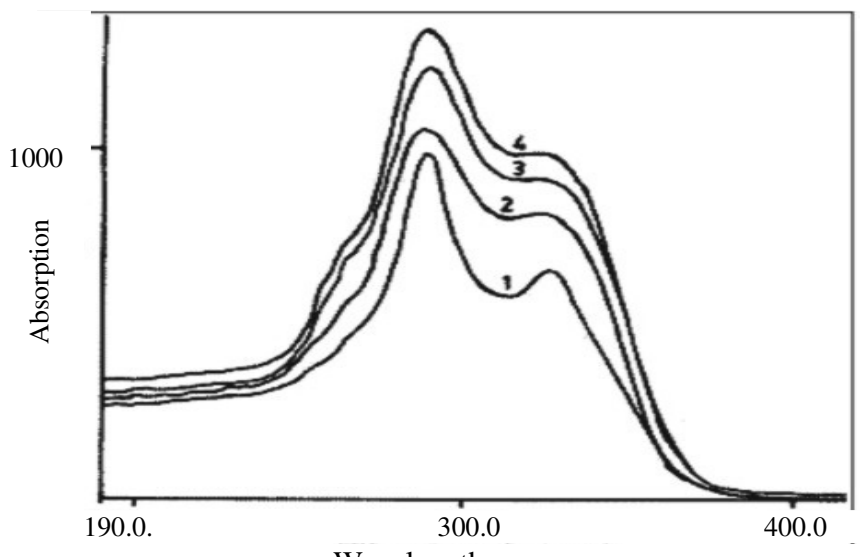

Wavelength $\mathrm{nm}$.

Figue 2. Electronic spectra of terpolymer resins (1) 2, 4-DHBOF-I, (2) 2, 4-DHBOF-II, (3) 2, 4-DHBOF-III, (4) 2, 4-DHBOF-IV.

The bathochromic shift (shift towards longer wavelength) from the basic value of the $\mathrm{C}=\mathrm{O}$ group viz. $310 \mathrm{~nm}$ and $240 \mathrm{~nm}$ respectively, may be due to the combine effect of conjugation and phenolic hydroxyl group (auxochrome) ${ }^{12,13}$. It may be observed from the electronic spectra of the 2, 4-DHBOF terpolymers that the absorption intensity gradually increases in the order 2,4-DHBOF -I $<2,4-$ DHBOF - II $<2,4-$ DHBOF - III $<2,4-$ DHBOF - IV. The observed increasing order may be due to introduction of more chromophores $(\mathrm{C}=\mathrm{O}$ group) and auxochromes (phenolic $\mathrm{OH})$ in the repeat unit structure of the terpolymers.

\section{Infrared spectra}

The IR-spectra of all four 2, 4-DHBOF terpolymers are presented in Figure 3. The IRspectra revealed that all these terpolymers give rise to nearly similar pattern of spectra (Table 3). A band appeared in the region $3337 \mathrm{~cm}^{-1}-3316 \mathrm{~cm}^{-1}$ may be assigned to the stretching vibration of the phenolic hydroxy groups exhibiting intermolecular hydrogen bonding ${ }^{12}$. The presence of weak peak at $2878 \mathrm{~cm}^{-1}-2878 \mathrm{~cm}^{-1}$ describes the $-\mathrm{NH}$ - in biuret moity may be ascribed in the terpolymeric chain ${ }^{12,13}$. The presence of methyl and methylene vibrations at $2950 \mathrm{~cm}^{-1}-2846 \mathrm{~cm}^{-1}$ gives sharp and weak peaks. The sharp band displayed at $1631 \mathrm{~cm}^{-1}-1628 \mathrm{~cm}^{-1}$ may be due to the stretching vibration of carbonyl group of both, ketonic as well as biuret moity ${ }^{14}$. The sharp and weak bond obtained at $1381 \mathrm{~cm}^{-1}-1380 \mathrm{~cm}^{-1}$ suggests the presence of $-\mathrm{CH}_{2}$ - methylene bridges ${ }^{15}$ in the terpolymer chain. The presence of $1,2,3,4,5$ - pentasubstitution of aromatic ring is recognized from the weak bond appearing at $898 \mathrm{~cm}^{-1}-897 \mathrm{~cm}^{-1}$ respectively ${ }^{15}$. 
Table 3. IR frequencies of 2, 4-DHBOF terpolymers resins.

\begin{tabular}{lcccc}
\hline \multirow{2}{*}{ Assignment } & \multicolumn{4}{c}{ Observed wave number, $\mathrm{cm}^{-1}$} \\
\cline { 2 - 5 } & $2,4-\mathrm{DHBOF}-\mathrm{I}$ & $2,4-\mathrm{DHBOF}-\mathrm{II}$ & $2,4-\mathrm{DHBOF}-\mathrm{III}$ & $2,4-\mathrm{DHBOF}-\mathrm{IV}$ \\
\hline -OH (phenolic) & $3335.5 \mathrm{~b}, \mathrm{st}$ & $3337.0 \mathrm{~b}, \mathrm{st}$ & $3323.1 \mathrm{~b}, \mathrm{st}$ & $3316.1 \mathrm{~b}, \mathrm{st}$ \\
$>\mathrm{NH}$ (amido) & $2878.9 \mathrm{sh}, \mathrm{w}$ & $2878.3 \mathrm{sh}, \mathrm{w}$ & $2878.6 \mathrm{sh}, \mathrm{w}$ & $2878.5 \mathrm{sh}, \mathrm{w}$ \\
$-\mathrm{CH}_{3},>\mathrm{CH}_{2}$ & $2850.3 \mathrm{sh}, \mathrm{w}$ & $2848.6 \mathrm{sh}, \mathrm{w}$ & $2847.8 \mathrm{sh}, \mathrm{w}$ & $2846.0 \mathrm{sh}, \mathrm{w}$ \\
$\begin{array}{l}\text { assymm, symm vib } \\
>\mathrm{C}=\mathrm{O} \text { (ketonic and }\end{array}$ & $1631.4 \mathrm{sh}, \mathrm{st}$ & $1631.4 \mathrm{sh}, \mathrm{st}$ & $1630.8 \mathrm{sh}, \mathrm{st}$ & $1628.9 \mathrm{sh}, \mathrm{st}$ \\
$\begin{array}{l}\text { biuret moity) } \\
\begin{array}{l}\text { Aromatic ring } \\
>\mathrm{CH}_{2} \text { (methylene }\end{array}\end{array}$ & $1475.7 \mathrm{sh}, \mathrm{w}$ & $1478.4 \mathrm{sh}, \mathrm{w}$ & $1479.0 \mathrm{sh}, \mathrm{w}$ & $1479.4 \mathrm{sh}, \mathrm{w}$ \\
$\begin{array}{l}\text { bridges) } \\
\begin{array}{l}1,2,3,4,5 \text { substitution } \\
\text { in benzene skeleton }\end{array}\end{array}$ & $897.7 \mathrm{sh}, \mathrm{w}$ & $898.7 \mathrm{sh}, \mathrm{w}$ & $898.3 \mathrm{sh}, \mathrm{w}$ & $898.1 \mathrm{sh}, \mathrm{w}$ \\
\hline
\end{tabular}

${ }^{1}$ H-nuclear magnetic resonance spectra

1H-NMR spectra of all the four 2, 4 DHBOF terpolymers were scanned in DMSO- $\mathrm{d}_{6}$. The spectral data are given in Table 3 and the spectra are presented in Figure 3. From the spectra it is revealed that all the 2, 4 DHBOF terpolymers gave rise to different pattern of 1H-NMR spectra, since each of the 2, 4 DHBOF terpolymers posses set of proton having different electronic environments.

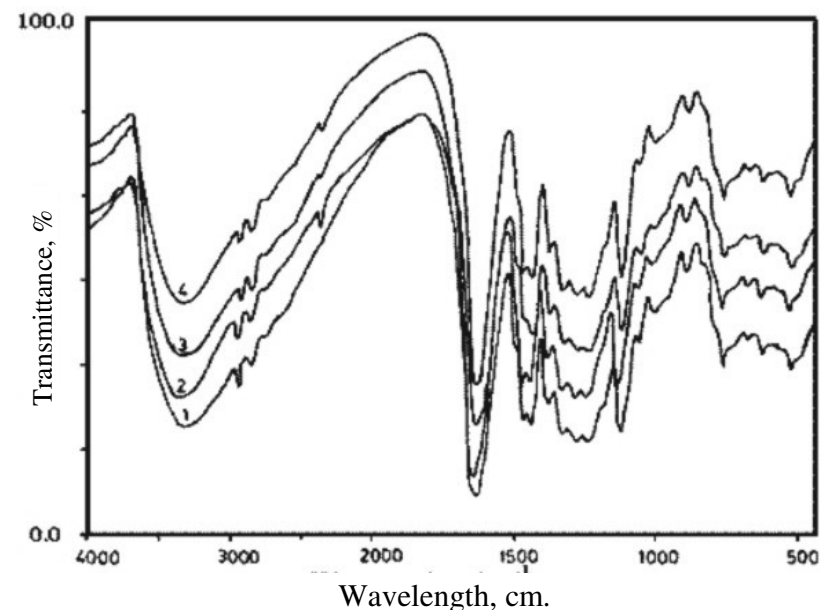

Figure 3. Infrared spectrum of terpolymer resins (1) 2, 4-DHBOF-I, (2) 2, 4-DHBOF-II, (3) 2, 4-DHBOF-III, 4) 2, 4-DHBOF-IV.

Except 2, 4 DHBOF-I and 2, 4 DHBOF-II the remaining two terpolymers viz. 2, 4 DHBOF-III and 2, 4 DHBOF-IV, exhibit singlet signal in the region $3.95 \mathrm{ppm}$ which are due to methylenic protons of $\mathrm{Ar}-\mathrm{CH}_{2}-\mathrm{Ar}$ bridge ${ }^{12,13}$. The weak multiplet signals (unsymmetrical pattern) in the region $7.37 \mathrm{ppm}$ are due to aromatic protons. The methylenic protons of the Ar$\mathrm{CH}_{2}-\mathrm{N}$ moiety may be recognized as signal appearing in the region $6.44 \mathrm{ppm}^{12,13}$. The signal in the region $6.66 \mathrm{ppm}$ are attributed to the protons of $-\mathrm{NH}$ - bridges. A medium singlet peaks appeared at $9.51 \mathrm{ppm}$ may be assigned to aldehydic protons of $\mathrm{Ar}-\mathrm{CHO}^{12,13}$. The signals in the range of $7.06 \mathrm{ppm}$ are attributed to phenolic hydroxyl protons. This significant downfield chemical shift of the proton of phenolic $\mathrm{OH}$ group clearly indicates intramolecular hydrogen bonding of $\mathrm{OH}$ with the carbonyl group present at the adjacent ortho position ${ }^{12,13}$. 
Table 4. ${ }^{1} \mathrm{H}$ NMR spectral data of 2, 4-DHBOF terpolymers resins in DMSO- $\mathrm{d}_{6}$

\begin{tabular}{|c|c|c|c|c|}
\hline \multicolumn{4}{|c|}{ Chemical shift $(\delta)$ ppm of terpolymer } & \multirow{2}{*}{ Nature of proton assigned } \\
\hline 2,4-DHBOF-I & 2,4-DHBOF-II & 2,4-DHBOF-III & 2,4-DHBOF-IV & \\
\hline 9.51 & 9.51 & 9.51 & 9.53 & $\begin{array}{c}\text { Aldehydic proton of } \\
\text { Ar- } \mathrm{CHO}\end{array}$ \\
\hline 7.37 & 7.37 & 7.38 & 7.38 & $\begin{array}{l}\text { Aromatic proton } \\
\text { (unssymm. Pattern) }\end{array}$ \\
\hline 7.07 & 7.08 & 7.06 & 7.06 & $\begin{array}{l}\text { Proton of Ar-OH } \\
\text { (phenolic }-\mathrm{OH})\end{array}$ \\
\hline 6.66 & 6.66 & 6.66 & 6.66 & $\begin{array}{c}\text { Amido proton of } \\
-\mathrm{CH}_{2}-\mathrm{NH}-\mathrm{CO}-\text { linkage }\end{array}$ \\
\hline 6.56 & 6.44 & 6.45 & 6.44 & $\begin{array}{l}\text { Methylene proton of } \\
\text { Ar- } \mathrm{CH}_{2}-\mathrm{NH} \text { moity }\end{array}$ \\
\hline-- & -- & $3.95 \mathrm{~s}$ & $3.95 \mathrm{~s}$ & $\begin{array}{l}\text { Methylene proton of } \\
\mathrm{Ar}-\mathrm{CH}_{2}-\mathrm{Ar} \text { linkage }\end{array}$ \\
\hline
\end{tabular}

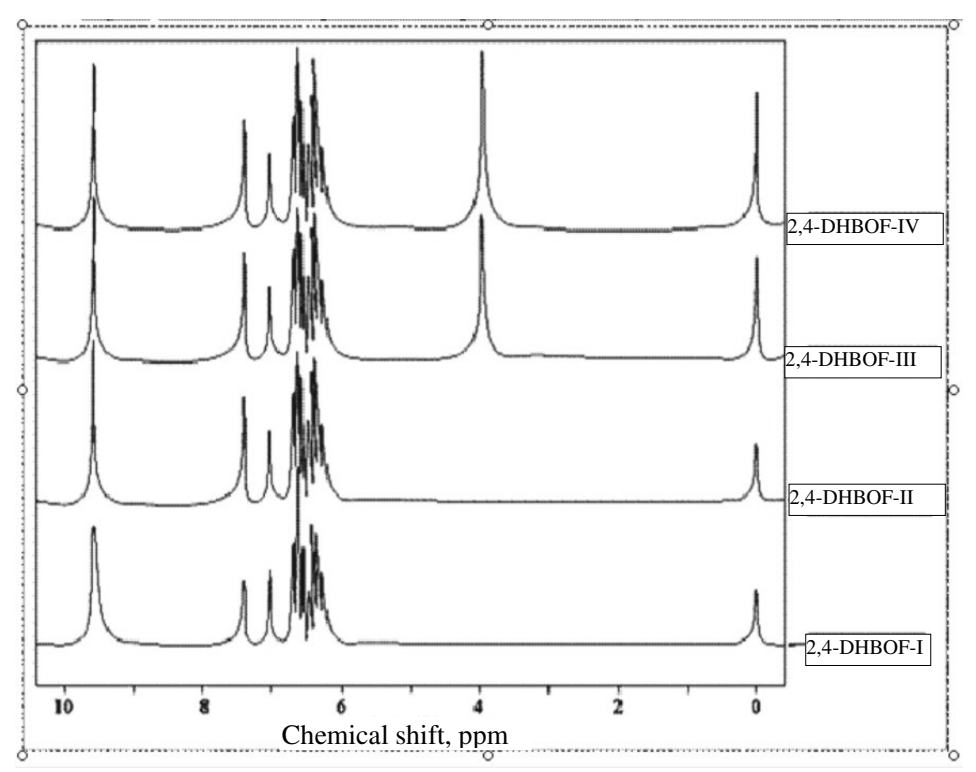

Figure 4. Proton NMR Spectra of Terpolymer Resin (1) 2, 4-DHBOF-I, (2) 2, 4-DHBOFII, (3) 2, 4-DHBOF-III, (4) 2, 4-DHBOF-IV.

On the basis of the nature and reactive position of the monomer elemental analysis, electronic, IR, NMR spectra and molecular weight, the most probable structures have been proposed for these terpolymers as shown in Figure 5.

\section{Ion-exchange properties}

The results of the batch equilibrium study carried out with the terpolymer samples 2, 4-DHBOFI, 2, 4-DHBOF-II, 2, 4-DHBOF-III and 2, 4-DHBOF-IV are presented in Tables 5 - 7. From the study with eight metal ions under limited variation of experimental conditions, certain generalization may be made about the behavior of the terpolymer sample. 

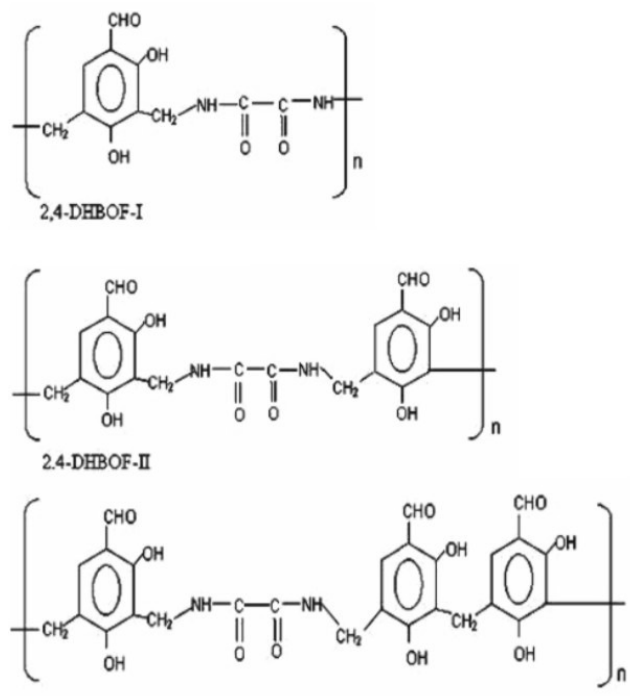

2,4-DHBOF-III

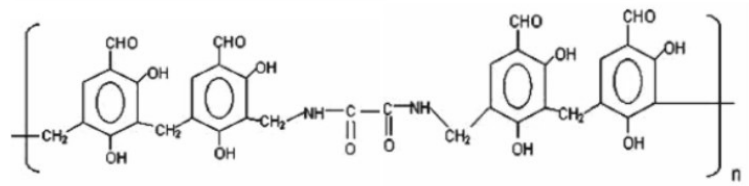

2,4-DHBOF-IV

Figure 5. The suggested structures of 2, 4-DHBOF terpolymer resins.

\section{Effect of Electrolytes on Metal Uptake}

We examine the effect of $\mathrm{NO}_{3}^{-}, \mathrm{Cl}^{-}, \mathrm{ClO}_{4}^{-}$and $\mathrm{SO}_{4}^{-2}$ at various concentrations on the equilibrium of metal-resin interaction. Table 5 shows that the amount of metal ions taken up by a given amount of terpolymer depends on the nature and concentration of the electrolyte present in the solution. In the presence of nitrate, chloride and perclorate ions the uptake of $\mathrm{Fe}^{+3}, \mathrm{Cu}^{+2}, \mathrm{Hg}^{+2}, \mathrm{Cd}^{+2}, \mathrm{Co}^{+2}, \mathrm{Zn}^{+2}, \mathrm{Ni}^{+2}$ and $\mathrm{Pb}^{+2}$ ions increasing with increasing concentration of electrolytes. However in the presence of sulphate ions the uptake capacity decreases with increasing concentration. Moreover the uptake of $\mathrm{Fe}^{+3}, \mathrm{Cd}^{+2}, \mathrm{Co}^{+2}$ ions increases with increasing concentration of nitrate, chloride and perclorate ions ${ }^{16-18}$ as compare to $\mathrm{Cu}^{+2}, \mathrm{Hg}^{+2}, \mathrm{Zn}^{+2}, \mathrm{Ni}^{+2}$ and $\mathrm{Pb}^{+2}$ ions whereas decreases in presence of sulphate ions. Above nitrate, chloride and perclorate ions form weak complex with the above metal ions while sulphate ions form stronger complex thus the equilibrium is affected This may be explained on the basis of the stability constants of the complexes with those metal ions ${ }^{16-18}$. This type of trends has been observed by the other investigator in this field.

\section{Rate of metal Ion uptake}

The rate of metal adsorption was determined to find out the shortest period of time for which equilibrium could be carried out while operating as close to equilibrium condition as possible. Table 6 show the dependence of the rate of metal ion uptake on the nature of the metal. The rate refers to the change in the concentration of metal ions in the aqueous solution, which is in contact with the given polymer. The results showed that the time taken for the uptake of the different metal ions at a given stage depends on the nature of the metal ion under given conditions. 
It is found that $\mathrm{Fe}^{+3}$ ions required about $3 \mathrm{~h}$ for the establishment of the equilibrium, whereas $\mathrm{Cu}^{+2}$, $\mathrm{Hg}^{+2}, \mathrm{Cd}^{+2}, \mathrm{Co}^{+2}, \mathrm{Zn}^{+2}, \mathrm{Ni}^{+2}$ and $\mathrm{Pb}^{+2}$ ions required about $6 \mathrm{~h}$. Thus, the rate of metal ion uptake follows the order $\mathrm{Fe}^{+3}>>\mathrm{Cd}^{+2}>\mathrm{Co}^{+2}>\mathrm{Hg}^{+2}>\mathrm{Zn}^{+2}>\mathrm{Pb}^{+2}>\mathrm{Cu}^{+2}>\mathrm{Ni}^{+2}$ for the terpolymer ${ }^{16-18}$.

Table 5. Evaluation of the effect of different electrolytes on the uptake of several metal ions ${ }^{\mathrm{a}}$ by 2,4-DHBOF-I terpolymers resins.

\begin{tabular}{|c|c|c|c|c|c|c|}
\hline \multirow{2}{*}{$\begin{array}{c}\text { Metal } \\
\text { ion }\end{array}$} & \multirow{2}{*}{$\begin{array}{c}\text { Electrolyte } \\
\mathrm{mol} / \mathrm{L}\end{array}$} & \multirow{2}{*}{$\mathrm{pH}$} & \multicolumn{4}{|c|}{ Weight $(\mathrm{mg})$ of metal ion taken up in the presence of } \\
\hline & & & $\mathrm{NaClO}_{4}$ & $\mathrm{NaCl}$ & $\mathrm{NaNO}_{3}$ & $\mathrm{Na}_{2} \mathrm{SO}_{4}$ \\
\hline \multirow{5}{*}{$\mathrm{Fe}^{+3}$} & 0.01 & \multirow{5}{*}{2.5} & 0.10 & 0.13 & 0.18 & 0.69 \\
\hline & 0.05 & & 0.15 & 0.21 & 0.27 & 0.62 \\
\hline & 0.10 & & 0.29 & 0.34 & 0.44 & 0.48 \\
\hline & 0.50 & & 0.62 & 0.64 & 0.67 & 0.43 \\
\hline & 1.00 & & 0.70 & 0.71 & 0.72 & 0.34 \\
\hline \multirow{5}{*}{$\mathrm{Cu}^{+2}$} & 0.01 & \multirow{5}{*}{4.5} & 0.02 & 0.04 & 0.03 & 0.58 \\
\hline & 0.05 & & 0.04 & 0.07 & 0.08 & 0.49 \\
\hline & 0.10 & & 0.11 & 0.21 & 0.20 & 0.41 \\
\hline & 0.50 & & 0.34 & 0.57 & 0.34 & 0.31 \\
\hline & 1.00 & & 0.58 & 0.66 & 0.49 & 0.20 \\
\hline \multirow{5}{*}{$\mathrm{Hg}^{+2}$} & 0.01 & \multirow{5}{*}{6.0} & 0.20 & 0.25 & 0.41 & 2.38 \\
\hline & 0.05 & & 0.29 & 0.37 & 0.73 & 2.12 \\
\hline & 0.10 & & 0.62 & 0.89 & 1.19 & 1.61 \\
\hline & 0.50 & & 1.88 & 2.01 & 2.01 & 1.43 \\
\hline & 1.00 & & 2.17 & 2.35 & 2.31 & 1.12 \\
\hline \multirow{5}{*}{$\mathrm{Cd}^{+2}$} & 0.01 & \multirow{5}{*}{5.0} & 0.15 & 0.23 & 0.30 & 1.20 \\
\hline & 0.05 & & 0.23 & 0.32 & 0.44 & 1.08 \\
\hline & 0.10 & & 0.50 & 0.58 & 0.76 & 0.87 \\
\hline & 0.50 & & 1.18 & 1.24 & 1.26 & 0.76 \\
\hline & 1.00 & & 1.35 & 1.40 & 1.43 & 0.53 \\
\hline \multirow{5}{*}{$\mathrm{Co}^{+2}$} & 0.01 & \multirow{5}{*}{5.0} & 0.06 & 0.09 & 0.19 & 0.40 \\
\hline & 0.05 & & 0.10 & 0.12 & 0.27 & 0.30 \\
\hline & 0.10 & & 0.20 & 0.27 & 0.42 & 0.20 \\
\hline & 0.50 & & 0.58 & 0.62 & 0.63 & 0.16 \\
\hline & 1.00 & & 0.67 & 0.71 & 0.70 & 0.09 \\
\hline \multirow{5}{*}{$\mathrm{Zn}^{+2}$} & 0.01 & \multirow{5}{*}{5.0} & 0.05 & 0.06 & 0.16 & 0.64 \\
\hline & 0.05 & & 0.07 & 0.10 & 0.25 & 0.50 \\
\hline & 0.10 & & 0.13 & 0.26 & 0.39 & 0.41 \\
\hline & 0.50 & & 0.44 & 0.62 & 0.53 & 0.37 \\
\hline & 1.00 & & 0.66 & 0.73 & 0.62 & 0.26 \\
\hline \multirow{5}{*}{$\mathrm{Ni}^{+2}$} & 0.01 & \multirow{5}{*}{4.5} & 0.01 & 0.02 & 0.01 & 0.46 \\
\hline & 0.05 & & 0.02 & 0.07 & 0.001 & 0.35 \\
\hline & 0.10 & & 0.08 & 0.12 & 0.003 & 0.27 \\
\hline & 0.50 & & 0.27 & 0.20 & 0.005 & 0.23 \\
\hline & 1.00 & & 0.48 & 0.33 & 0.007 & 0.14 \\
\hline \multirow{5}{*}{$\mathrm{Pb}^{+2}$} & 0.01 & \multirow{5}{*}{6.0} & 0.13 & 0.20 & 0.37 & 1.80 \\
\hline & 0.05 & & 0.20 & 0.2 & 0.56 & 1.47 \\
\hline & 0.10 & & 0.38 & 0.77 & 0.93 & 1.21 \\
\hline & 0.50 & & 1.27 & 1.91 & 1.50 & 0.98 \\
\hline & 1.00 & & 2.01 & 2.25 & 1.83 & 0.71 \\
\hline
\end{tabular}

${ }^{a}\left[\mathrm{M}\left(\mathrm{NO}_{3}\right)_{2}\right]=0.1 \mathrm{~mol} / \mathrm{L}$; Volume $=2 \mathrm{~mL} ;$ Volume of electrolyte solution $=25 \mathrm{~mL}$;

Weight of resin $=25 \mathrm{mg}$; Time $=24$ h at room temperature. 
Table 6. Comparison of the rates of metal $(\mathrm{M})$ ion uptake ${ }^{\mathrm{a}}$ by 2, 4-DHBOF-I terpolymers resins.

\begin{tabular}{ccccccc}
\hline \multirow{2}{*}{ Metal ion } & \multicolumn{5}{c}{ \% of metal ion uptake ${ }^{\mathrm{b}}$ at different time $(\mathrm{h})$} \\
\cline { 2 - 7 } & 1 & 2 & 3 & 4 & 5 & 6 \\
\hline $\mathrm{Fe}^{+3}$ & 45.5 & 69.5 & 98.0 & - & - & - \\
$\mathrm{Cu}^{+2}$ & 5.5 & 15.5 & 29.5 & 36.0 & 49.0 & 59.0 \\
$\mathrm{Hg}^{+2}$ & 10.5 & 16.5 & 19.5 & 39.5 & 61.0 & 86.5 \\
$\mathrm{Cd}^{+2}$ & 9.0 & 11.0 & 24.5 & 49.5 & 69.5 & 95.5 \\
$\mathrm{Co}^{+2}$ & 6.5 & 20.5 & 39.5 & 59.5 & 68.5 & 90 \\
$\mathrm{Zn}^{+2}$ & 2.5 & 10.5 & 24.5 & 44.0 & 57.5 & 72.0 \\
$\mathrm{Ni}^{+2}$ & - & - & 0.25 & 0.50 & 0.75 & 1.0 \\
$\mathrm{~Pb}^{+2}$ & 4.0 & 13.5 & 26.5 & 64.5 & 65.5 & 66.5 \\
\hline
\end{tabular}

${ }^{a}\left[\mathrm{M}\left(\mathrm{NO}_{3}\right)_{2}\right]=0.1 \mathrm{~mol} / \mathrm{L}$; Volume $=2 \mathrm{~mL} ;$ Volume of electrolyte solution $=25 \mathrm{~mL} ;$ Weight of resin $=$ $25 \mathrm{mg} ;$ Time $=24 \mathrm{~h}$ at room temperature. ${ }^{b}$ Metal ion uptake $=($ amount of metal ion absorbed $\times 100) /$ amount of metal ion absorbed at equilibrium.

Table 7. Distribution ratio $\mathrm{D}^{\mathrm{a}}$ of various metal ion as a function of the $\mathrm{pH}^{\mathrm{b}}$ by 2 , 4-DHBOFI terpolymers resins.

\begin{tabular}{ccccccccccc}
\hline Metal & \multicolumn{10}{c}{ Distribution ratio of metal ion at different $\mathrm{pH}$} \\
\cline { 2 - 12 } ion & 1.5 & 1.75 & 2.0 & 2.5 & 3.0 & 3.5 & 4.0 & 5.0 & 6.0 & 6.5 \\
\hline $\mathrm{Fe}^{+3}$ & 87.12 & 136.14 & 212.42 & 4355.55 & - & - & - & - & - & - \\
$\mathrm{Cu}^{+2}$ & - & - & - & 59.25 & 65.70 & 69.84 & 120.26 & 133.33 & 1688.88 & - \\
$\mathrm{Hg}^{+2}$ & - & - & - & 33.71 & 110.86 & 127.91 & 378.94 & 524.13 & 569.54 & 757.67 \\
$\mathrm{Cd}^{+2}$ & - & - & - & 207.40 & 334.39 & 484.58 & 1022.22 & 1886.42 & 3861.72 & 5837.03 \\
$\mathrm{Co}^{+2}$ & - & - & - & 20.85 & 85.40 & 207.40 & 449.83 & 1096.29 & 2133.33 & 5837.03 \\
$\mathrm{Zn}^{+2}$ & - & - & - & 37.19 & 82.05 & 106.47 & 172.54 & 266.66 & 1392.59 & 3466.66 \\
$\mathrm{Ni}^{+2}$ & - & - & - & - & - & - & 0.49 & 0.89 & 3.22 & 5.03 \\
$\mathrm{~Pb}^{+2}$ & - & - & - & 38.09 & 55.64 & 72.72 & 92.51 & 130.58 & 176.45 & 259.69 \\
\hline
\end{tabular}

${ }^{a} \mathrm{D}=$ Weight $(\mathrm{mg})$ of metal ion taken up by $1 \mathrm{~g}$ of terpolymer/ Weight $(\mathrm{mg})$ of metal ions present in 1

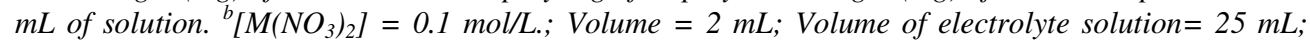
Weight of resin $=25 \mathrm{mg}$; Time $=24$ h (equilibrium state), at room temperature.

\section{Distribution ratios of metal Ions at different $\mathrm{pH}$}

The effect of $\mathrm{pH}$ on the amount of metal ions distributed between two phases can be explained by the results given in Table 7 . The data on the distribution ratio as a function of $\mathrm{pH}$ indicate that the relative amount of metal ions taken up by the terpolymers increases with increasing $\mathrm{pH}$ of the medium ${ }^{16-18}$. The magnitude of increase, however, is different for different metal ions. The selectivity of $\mathrm{Fe}(\mathrm{III})$ ion is more for the 2, 4-DHBOF terpolymer resins as compare to the any other metal ions under study. The order of distribution ratio of metal ions measured in the $\mathrm{pH}$ range 1.5 to 6.5 is found to be $\mathrm{Fe}^{+3}>>\mathrm{Cd}^{+2} \approx \mathrm{Co}^{+2}>\mathrm{Zn}^{+2}>\mathrm{Cu}^{+2}>\mathrm{Hg}^{+2}>$ $\mathrm{Pb}^{+2}>\mathrm{Ni}^{+2}$. Thus the results of such type of study are helpful in selecting the optimum $\mathrm{pH}$ for a selective uptake of a particular metal ion from a mixture of different metal ions ${ }^{16-18}$. For example, the result suggests the optimum $\mathrm{pH} 2.5$ for the separation of $\mathrm{Fe}^{+3}$ and $\mathrm{Co}^{+2}$ or $\mathrm{Cd}^{+2}$ the distribution ratios ' $\mathrm{D}$ ' as 4355.55 and 5837.03 respectively using the 2,4-DHBOF-I terpolymer resin as ion exchanger. Similarly for the separation of $\mathrm{Fe}^{+3}$ and $\mathrm{Pb}^{+2}$ (II) at the optimum $\mathrm{pH}$ is 2.5 the distribution ratios are 4355.55 and 259.69 respectively for 2, 4-DHBOF-I terpolymer. The lowering in the distribution ratio of $\mathrm{Fe}^{+3}$ was found to be small and hence, efficient separation could be achieved. Thus the separation of $\mathrm{Fe}^{+3}$ from other metals having combination (1) $\mathrm{Fe}^{+3}$ and $\mathrm{Cu}^{+2}$ (2) $\mathrm{Fe}^{+3}$ and $\mathrm{Hg}^{+2}$ (3) $\mathrm{Fe}^{+3}$ and $\mathrm{Zn}^{+2}$ (4) $\mathrm{Fe}^{+3}$ and $\mathrm{Pb}^{+2}$ (5) (4) $\mathrm{Cu}^{+2}$ and $\mathrm{Cd}^{+2}$ are effectively may separate out. 


\section{Conclusion}

1) The 2,4-DHBOF terpolymer based on the condensation polymerization of 2,4dihydroxybenzaldehyde and oxamide with formaldehyde in the presence of acid catalyst has been prepared.

2) The 2,4-DHBOF terpolymer is a selective chelating ion exchange polymer for certain metals.

3) The terpolymer showed ahigher selectivity for $\mathrm{Fe}^{+3}, \mathrm{Cd}^{+2}$ and $\mathrm{Co}^{+2}$ than for $\mathrm{Cu}^{+2}, \mathrm{Hg}^{+2}$, $\mathrm{Zn}^{+2}, \mathrm{Ni}^{+2}$ and $\mathrm{Pb}^{+2}$ ions.

\section{Acknowledgement}

Authors are thankful to the Director, Laxminarayan Institute of Technology, R.T.M. Nagpur University, Nagpur for providing laboratory facilities and also thankful to SAIF, Punjab University, Chandigarh for carrying out spectral analysis.

\section{References}

1 Helfferich F, Ion Exchange Resins, Mc-Grow Hill:New York, 1962.

2 Kunin R, Ion Exchange Resins, $3^{\text {rd }}$ Ed; Wiley:New York, 1958.

3 Lutfor MR and Silong S, Eur Polym J., 2000, 36, 2105.

$4 \quad$ Patel S A, Shah B S and Patel R M, Iran Polym J., 2004, 13(6), 445.

5 Ibraheem K A K, Al-duhan J A and Himdi S T, Eur Polym J., 1985, 21, 97.

6 Dass S C, J Indian Chem Soc., 2000, 77, 69.

7 Rivas BL and Villegas SJ, Munoz C, J App Polym Sci., 2004, 19(6), 3679-3685.

8 Jadhao M M, Paliwal L J and Bhave N S, J Appl Polym Sci., 2008, 109(1), 508-514.

$9 \quad$ Patel J R, Sutariya D H and Patel M N, React Polym., 1995, 25, 17.

10 Lingala P S, Paliwal L J and Juneja H D, Proc Nat Acad Sci., 2001, 71(A), 205.

11 Michael PE P, Lingala P S, Juneja H D and Paliwal L J, J Appl Polym Sci., 2004, 92(4), 2278.

12 Silverstein R M and Basslel G C, Spectrometric Identification of Organic Compounds. $2^{\text {nd }}$ Ed., Wiley, New York, 1987.

13 Dudley $\mathrm{H}$ and Fleming I, Spectroscopic methods in Organic Chemistry, Mc-Graw Hill, U.K., 1975.

14 Patel M M, Kapadiya M A, Patel G P and Joshi J D, J Appl Polym Sci., 2006, 106(2), 1307.

15 Stuart B H, Infrared Spectroscopy: Fundamentals and Applications, John Wiley and Sons, U. K., 2004, 74.

16 Rath D K, Lenka S and Nayak P L, J Appl Polym Sci., 2003, 46(12), 2109.

17 Bastia T K, Lenka S and Nayak P L, J Appl Polym Sci., 2003, 46(4), 739.

18 Aich R, Lenka S and Nayak P L, J Appl Polym Sci., 2003, 34(3), 319. 


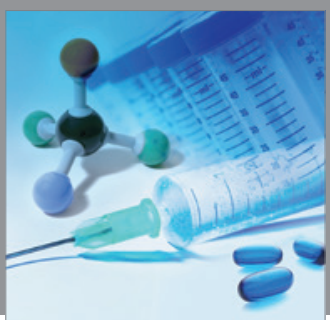

International Journal of

Medicinal Chemistry

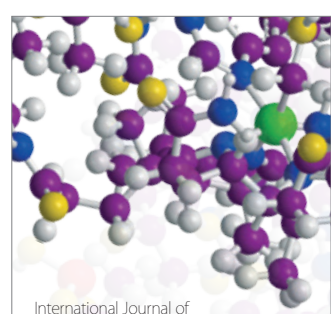

Carbohydrate Chemistry

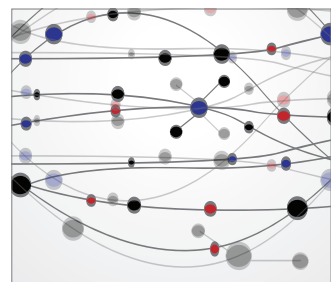

The Scientific World Journal
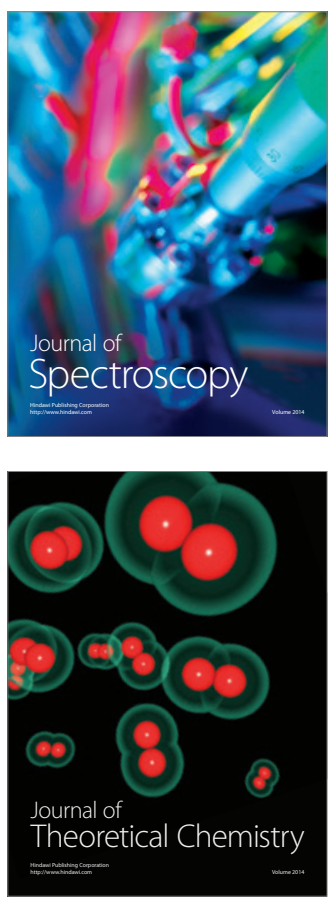
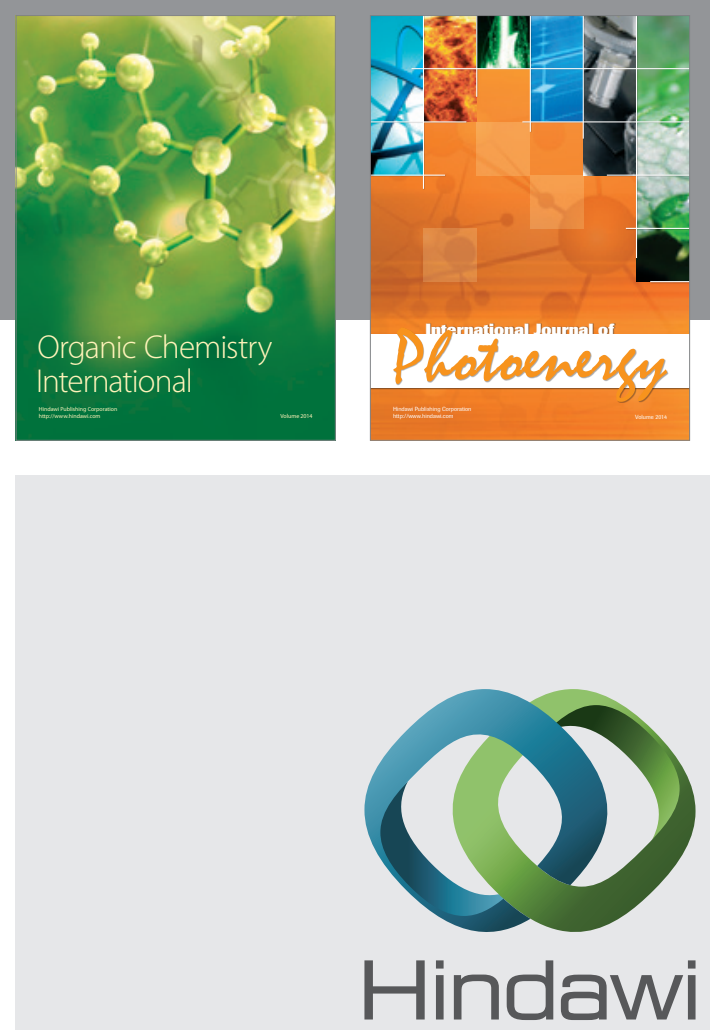

Submit your manuscripts at

http://www.hindawi.com
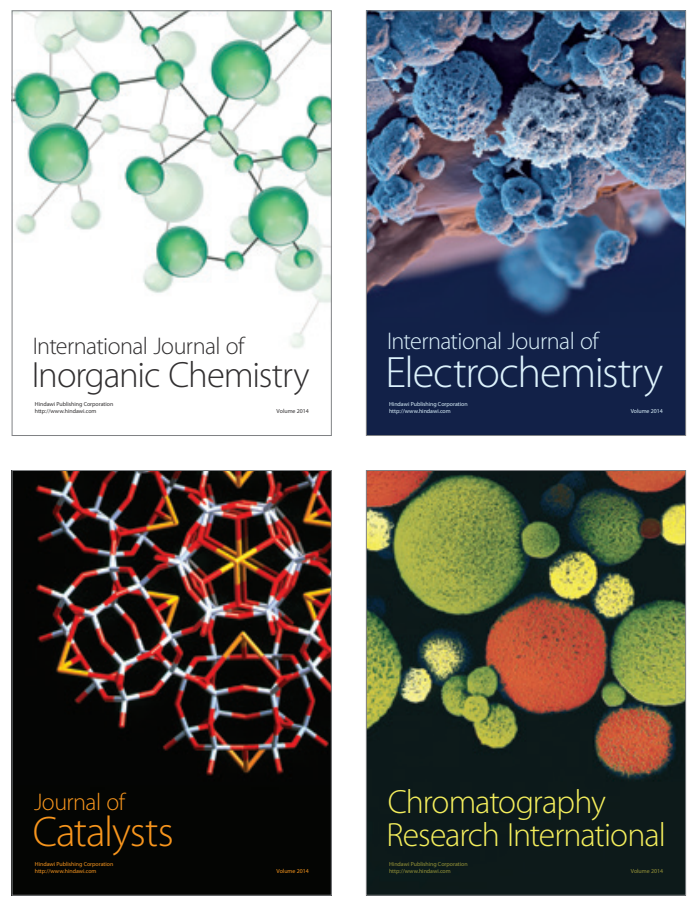
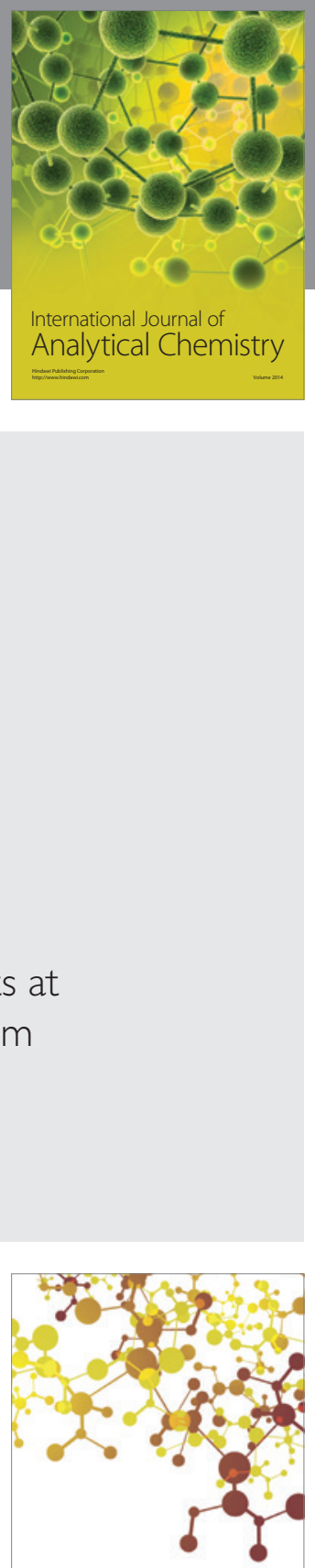

Journal of

Applied Chemistry
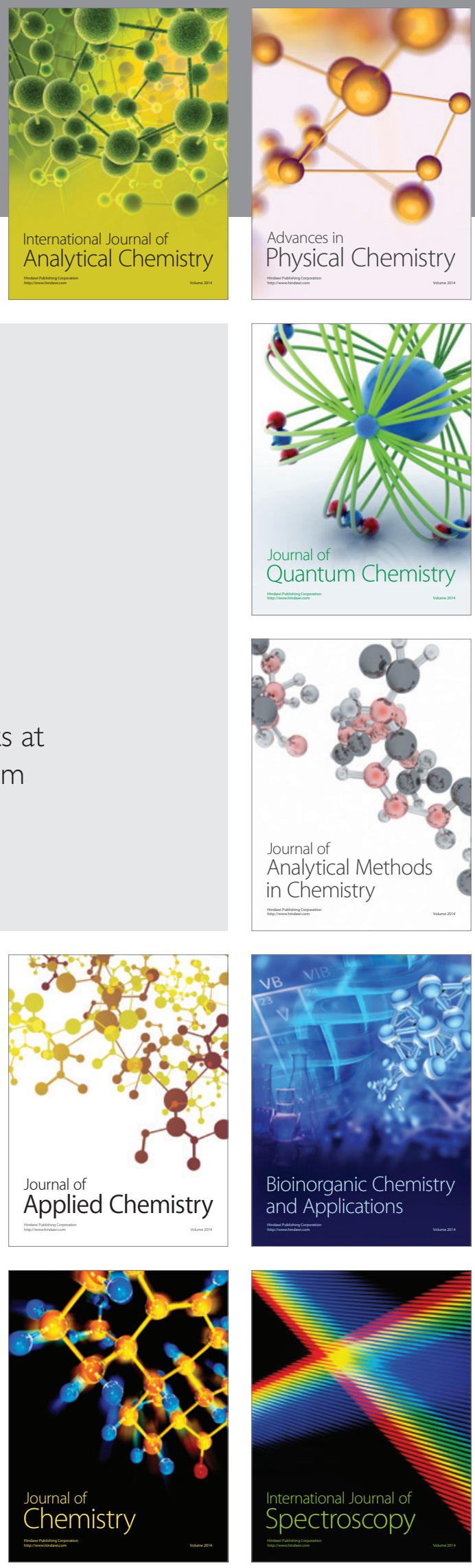